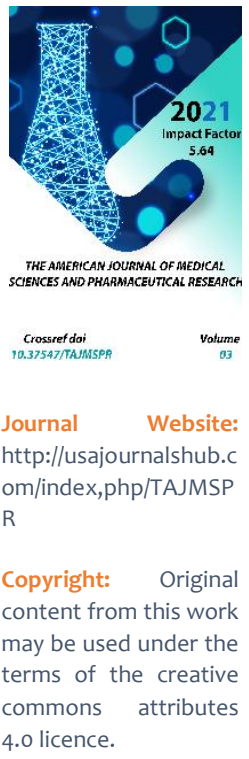

\title{
Clinical, Immunological And Molecular-Genetic Characteristic Of Aggressive Pituitary Adenomas
}

\author{
Khalimova Zamira Yusufovna \\ Republican Specialized Scientific-Practical Medical Center Of Endocrinology Named After \\ Academicianya.Kh. Turakulov, Tashkent Pediatric Medical Institute, Uzbekistan \\ Azimova Ozoda Tal'Atovna \\ Republican Specialized Scientific-Practical Medical Center Of Endocrinology Named After \\ Academicianya.Kh. Turakulov, Uzbekistan
}

\section{ABSTRACT}

Pituitary adenomas (PA) are monoclonal tumors arising from the cells of the adenohypophysis and represent approximately 10-15\% of all intracranial tumors and $90 \%$ of the tumors of the sellaturcica. Pituitary adenomas occur in almost $20 \%$ of the general population. The estimated annual morbidity of pituitary adenoma is approximately 20 cases per 100,000 of population, making it the third most common primary intracranial tumor after gliomas and meningiomas [9].

\section{KEYWORDS}

Pituitary adenomas, Epidemiology, Invasiveness criteria, APA,

\section{INTRODUCTION}

Morphological diagnostics takes an important place in the complex treatment of pituitary adenomas, thereby determining the effectiveness and tactics of further conducting and treatment of patients with hypertension.
Consequently, great interest in the study of the previous criteria for the development of pituitary adenomas has been taking place for a long time, but attempts to link the histological variant of adenoma, hormonal activity, and the 
number of mitoses with the prognosis for the patient have not been justified. Nowadays, the discussion about various expression of antibodies in adenomas and genetic markers continues.

The adenohypophysis is formed at the early stages of embryogenesis from invagination of the primary oral fissure - called Rathke's pocket under the influence of transcription factors (TF). A number of different transcript factors regulating the transformation of pituicite precursor cells into mature hormoneproducing secretory cells have been studied. Important transcription factors include Prop-1, Pit-1, Pitx-1, Ptx2, Gata2, NeuroDI, SFI, RPx / Hesl,, Lhx3 / L1M3 / P-Lim. At the stage of embryogenesis, the each transcript factor is involved in the differentiation pathway of the hormonal profile [4] and it is assumed that these transcript factors have an important role in the oncogenesis of pituitary adenomas.The question of plurigormonal cells, which are also found in the normal pituitary gland and in adenomas, remains open. Moreover, the pathogenesis of plurigormonal and monohormonaladenomas of the pituitary gland is not clear, which prompts to the deeper study of the molecular biology of the development of PA. The study of the expression of TF in pituitary adenomas allows us to consider them as a putative target for targeted therapy. Despite various hypotheses about the pathogenesis of the effect of TF on the development of pituitary adenomas in humans and the contradictory data of their activity, there is a lack of understanding of the real function of these factors and, therefore, the relevance of studying this area is increasing [42].

Pituitary adenomas can be classified as invasive or aggressive. According to the WHO (2014) classification, both typical and atypical adenomas can demonstrate an invasive nature and / or have an aggressive clinical course. For this reason, the terms "invasive" and "aggressive" should not be used interchangeably. Currently, aggressiveness is determined by clinical behavior, and invasiveness is determined visually by radiological, surgical and histopathological data.

There are key criteria that determine the aggressive course of pituitary adenomas. According to the classification of the Response Evaluation Criteria in Solid Tumors (RECIST) A significant tumor growth is considered to be a $20 \%$ increase in tumor within 6 months. However, for pituitary adenomas, this criterion is considered adequate if the growth is $>20 \%$, despite adequate surgical, drug and radiation therapy [19].

In this review, we emphasize the need to use specific biomarkers for the diagnosis of aggressive pituitary adenomas and focus on the definitions of these markers for the early diagnosis of this disease.

\section{Epidemiology}

Interpreting earlier epidemiological data on the morbidity of aggressive pituitary adenomas is challenging, and it is only in the last decade that more intensive population studies have emerged to assess their true burden of disease and associated pathologies. Some studies provided data on the prevalence of the disease [1] and some on the morbidity rates. These studies show an increase in both prevalence and morbidity. In the studies remains unclear if some of the results of epidemiological studies are related to specific populations, genetics, regions or time periods.

Due to the lack of definitive diagnostic criteria, the prevalence of aggressive pituitary adenomas (APA) is unclear $[45,46]$. The study, including radiographic and histological 
assessments of aggressiveness, found tumors of "grade $2 \mathrm{~b}$ " (invasive and proliferative) in 15\% of patients, although this was not a sequential series in which many patients were excluded due to insufficient data, and others were selected to balance patients with persistent disease and without it. Aggressiveness was also not unchanged in grade $2 \mathrm{~b}$ tumors [58]. Tumor recurrence and persistence, which are usually representative of APA, are more often observed in young people than in the elderly one [30]. APA in general is rare in children, but is usually more aggressive in pediatrics, with $26 \%$ of prolactinomas showing resistance to dopamine agonists [47]. Some studies [23], but not all show a high risk of relapse and progression in patients with large or giant PA.The development of APA is more likely in certain subtypes of tumors, namely inactive (Silent) corticotropnomas, cellular adenomas of the Crook's pituitary gland, plurigormonal PIT-1-positive PA (previously "silent subtype 3 PA"), rarely granular somatotropic PA and macroadenomas in particular prolactinomas in men [34].

A recent cohort study by the European Society of Endocrinology (ESE) has shown a correlation between the morbidityof aggressive pituitary adenomas and pituitary carcinomas (PC). The studied cohort consisted of 165 patients (40 PC, 125 APA), forming the largest APA / PC cohort to date. The morbidityof APA and PC were similar in age category at the time of diagnosis (43 vs 45 years), the prevailing subtypes of corticotropinoma cells in $45 \%$ with APA, and $48 \%$ in patients with PC. While prolactinomas in $20 \%$ with APA, while $38 \%$ of cases were reported in patients with PC.By functional status (clinically functioning in 58\% with APA, $63 \%$ with PC), but initially inactive PA (silent) and later functioning tumors were overrepresented in the group of patients with pituitary carcinoma (APA-7\% versus PC-20\%)
[30]. Both APA and PC showed a male predisposition (65\% versus $63 \%$ ) [31].

Adenoma of the pituitary gland caused by hypersecretion of growth hormone $(\mathrm{GH})$, and $\mathrm{GH}$-producing PA occur in $95 \%$ of patients with acromegaly. Although there is evidence that acromegaly can be caused by ectopic hypersecretion of $\mathrm{GH}[19,20]$ or excessive production of GH-releasing hormone [21], these etiologies are very rare. Since $\mathrm{GH}$ producing PAs account for the majority of cases of acromegaly, it is reasonable to assume that the prevalence and frequency of acromegaly are identical to those of $\mathrm{GH}$ producing PAs.According to large population studies published in 2000, the prevalence of hypertension producing $\mathrm{GH}$ was 3.3-13.7 cases per 100,000 population, and the annual morbidity is 0.2-1.1 cases per 100,000 population. These numbers are relatively higher than those previously reported before 2000 (prevalence: 3.8-6.9 per 100,000; annual incidence: $0.28-0.4$ per 100,000 ). Based on the clinical information of the studies conducted on cases of acromegaly, collected in all regions of the Republic of Uzbekistan showed only 526 cases of acromegaly for the period 2006-2019. Of these, 195 (37.5\%) cases were registered in men and $331(66 \%)$ cases in women.

Most pituitary tumors are slow-growing and benign. Their classification based on size or cell origin. Pituitary adenomas can be described as microadenomas, macroadenomas, and giant tumors, depending on their size. Microadenomas are tumors less than $10 \mathrm{~mm}$ in size, while macroadenomas include tumors larger than $10 \mathrm{~mm}$. Giant tumors of the pituitary gland are more than $40 \mathrm{~mm}$.[25].

The clinical behavior of pituitary tumors is highly variable, as some remain unchanged for long periods of time, and many grow slowly, 
while in rare cases there is rapid tumor growth. In the postoperative period, about $30 \%$ of patients show tumor growth after surgery, with an increased risk of tumor progression in the presence of a residual tumor.

There are functionally active pituitary adenomas, in which the type of cells of which they are composed causes an increased secretion of one or more hormones of the anterior pituitary gland. In addition, there are non-functional adenomas that do not secrete hormones, but they can affect the surrounding areas of the anterior pituitary gland, resulting to hormonal deficiency [48].

Despite the fact that pituitary adenomas are considered benign, up to $25-55 \%$ of them are invasive [10] and some exhibit clinically aggressive behavior.In addition, there is no clear definition of aggressive adenomas, but such tumors are usually considered from a clinical point of view as tumors with massive invasion of surrounding tissues, rapid growth, large size, a tendency to quickly recur, resistant to traditional methods of treatment, including radiation therapy [48] and in some patients, aggressiveness is fatal.

According to the previous classification of pituitary tumors by the World Health Organization (WHO), pituitary adenomas were subdivided into typical, atypical and pituitary carcinomas. According to classification 10 one of the key points is that pituitary carcinomas, by definition, are diagnosed only in the presence of craniospinal dissemination or systemic metastases, although not all of them have cytological signs of malignancy. Unlike pituitary carcinomas, aggressive pituitary adenomas do not metastasize, but the two classes may share some histological features [35].

Early diagnosis of aggressive pituitary tumors is challenging, but has great clinical importance, since they are associated with increased morbidity and mortality even in the absence of metastases [64]. Despite numerous studies and advances in prognostic classification, it has not yet been shown that any pathological marker reliably predicts the behavior of a pituitary tumor [46].

Most pituitary adenomas are characterized by uniform histological signs, rare mitotic parameters and a proliferative $\mathrm{Ki}-67$ index $<3 \%$. The term atypical adenoma is reserved for tumors that have atypical morphological features such as invasive growth [54], increased mitotic index, Ki-67 labeling index $\geq 3 \%$, and nuclear staining for the p53 cellular tumor antigen.By definition, pituitary carcinomas are only diagnosed when demonstrating craniospinal dissemination or systemic metastases, although not all of them exhibit classical cytotoxicity, histological features of malignancy such as pleomorphism

The main criteria for determining aggressiveness

Although atypical adenomas, based on the WHO classification, and clinically aggressive pituitary adenomas may have a similar clinical course, hormonal activity and radiological data, some features are characteristic only fortumors with an aggressive duration.

Prolactin-producing prolactinoma adenomas tend to be more common in women than in men, but more aggressive in men than in women [11]. Malignant prolactinomas may be resistant to dopamine agonists even at the start of therapy, or may become more aggressive over time, making response to therapy as independent predictor [17].

Tumors of the pituitary gland, consisting of cortikotorof cells, demonstrate an aggressive clinical course in terms of recurrence rate and invasiveness [2]. Silent or inactive corticotropic adenomas, defined as tumors lacking clinical or 
biochemical signs of hormone excess but morphologically similar to tumors producing ACTH, are usually more aggressive and recur more frequently than tumors associated with hypercortisolism [40] or non-functioning adenomas [28]. However, these results are inconsistent, and other studies have shown that silent corticotropic adenomas show increased invasion of the cavernous sinus compared to hormone-negative adenomas [27].

Thus, the main criteria for aggressiveness is based on:

- Clinical behavior

- Detection of abnormal cell proliferation such as high mitotic activity, Ki-67 $\geq 3 \%$ or immunopositivity to $\mathrm{p} 53$ protein)

- In general, APHs are invasive, macro- or giant adenomas, for example, with parasellar enlargement or bone invasion. A few exceptions have been described, such as aggressive ACTH-secreting microadenomas or other localized tumors characterized by a high recurrence rate or non-response to therapy.

\section{Invasiveness criteria}

Some pituitary adenomas can penetrate to surrounding structures, such as the wedgeshaped sinus or the cavernous sinus. Aggressive pituitary adenomas are usually invasive tumors, although invasiveness should not be confused with aggressiveness, as some tumors affecting surrounding structures do not exhibit aggressive behavior and constitute as weak tumors and responsive to conventional treatment [33]. However, tumor invasiveness is an important clinical indicator, since it is the main limitation for surgical resection of these tumors, and also associated with a large number of relapses after surgery [57].

In attempts to determine tumor invasion in the literature, histological, surgical and radiological criteria were used [24]. The histological criterion is based on the observation of microscopic invasive growth in the pia mater. However, its accuracy in detecting an aggressive tumor is low, since invasion into the dura mater is present in most macroadenomas and even in a significant proportion of microadenomas. In addition, the presence of microscopic dural invasion did not correlate with tumor behavior after surgery [36]. For these reasons, pathological analysis should not be used to determine tumor invasiveness.

According to published data, $25-55 \%$ of pituitary adenomas invade surrounding tissues such as the sphenoid sinus and / or cavernous sinus [49]. Invasion of the sphenoid sinus can be assessed by CT and / or MRI of the pituitary gland, or histologically, assessing mucosal invasion sphenoid sinus. There is a classification for the assessment of invasiveness according to Hard [18]. According to this classification, invasive adenomas can be either grade III, characterized by focal bone erosion, or grade IV, characterized by extensive bone erosion, including the base of the skull and extracellular structures.

In addition, there is a Knops classification. The Knosp grading system is used to quantify invasion in relation to the cavernous sinus, where only grades 3 and 4 determine true tumor invasion into the cavernous sinus.Grade o - no involvement of the cavernous sinus; Grades 1 and 2 - the tumor is pressed into the medial wall of the cavernous sinus, but does not go beyond a hypothetical line passing between the centers of two segments of the internal carotid artery (grade 1), or beyond such a line, but does not pass a line tangent to the lateral edges of the artery itself (degree 
2).); 3rd degree - the tumor extends laterally to the internal carotid artery in the cavernous sinus; 4th degree - complete sheath of the intracavernous carotid artery [58].

Thus, the main criteria of invasiveness is determined by the visual diagnostic method.

- According to Hardy's classification, invasive adenomas relate to grade III (focal bone erosion) and grade IV (extensive erosion of the bones of the skull base and parasellar structures)

- Knosp Grade 3 and Grade 4 define true tumor invasion into the cavernous sinus

- Macroadenomas can be invasive, but not often clinically aggressive

\section{Clinical characteristic of aggressive pituitary adenomas}

It is believed that APA almost always develop from pituitary macroadenomas (maximum tumor diameter $\geq 1 \mathrm{~cm}$ ) [43], but many macroadenomas and even giant prolactinomas $(\geq 4 \mathrm{~cm})$ respond well to standard medical treatment and in rare cases never show an aggressive course. The progression of microadenoma $(<1 \mathrm{~cm})$ to APA is extremely rare $(42,43)$. The time from the initial diagnosis with a pituitary neoplasm to the presentation of APA varies greatly, which is often not recorded [46].In APA, aggressiveness can manifest itself from the moment of diagnosis or develop from several months to more than ten years.

The course of APA can be interrupted by periods of radiological and hormonal remission, which does not exclude aggressiveness [38]. One study showed that APA more often occurs after incomplete surgery [23] but another study did not show any association between APA and primary surgical outcome. These conflicting results partially reflect the difficulty in distinguishing residual tumor from normal tissue and postoperative changes [65].

Some symptoms, such as headache and loss of visual field, are close and similar between PA, APA, and PC, while cranial nerve palsies and obstructive hydrocephalus are more suspicious for PA and PC [28]. Patients with Nelson's syndrome, which is inherently an aggressive neoplasm, often have massive effects, including cranial neuropathies from a growing primary tumor, as well as hyperpigmentation from excess proopiomelanocortin; distant metastases can also occur [44].

Important differential diagnoses are breast and lung carcinomas, which are the most common primary neoplasms that metastasize to the sellaturcica [6]. Small cell lung cancer can cause both ectopic ACTH syndrome and metastasis to the sellaturcica, which can be misdiagnosed as corticotropic pituitary carcinoma with distant metastasis [49]. PC metastases can lead to other specific clinical signs such as hearing loss, ataxia, motor weakness, back pain, neck masses, and liver dysfunction [14]

Yoo et al (2018) showed that the definition of metastases by the craniospinal method in 58\% of cases, systemic in 32\%, and both craniospinal and systemic in $8 \%$ of cases confirms the diagnosis of pituitary carcinomas, while PA does not tend to metastases. The main tissues of metastasis include the brain (43\%), spine (38\%), liver (14\%), cervical lymph nodes (11\%), and bones (10\%). In the central nervous system, metastases usually affect the cerebral cortex, cerebellum, and cerebellar angle [20]. Dural metastases can occur and may be misdiagnosed as meningiomas. 
The cell subtype of pituitary carcinomas can influence the nature and route of metastasis. With lactotropic PC, compared with corticotropic PC, systemic metastases are relatively more common $(71 \%$ and $57 \%$, respectively), and the duration of diagnosis of a pituitary neoplasm before the diagnosis of PC is shorter (4.7 and 9.5 years, respectively). In patients with distant metastases, the most common site of metastasis is the bone in lactotropic pituitary carcinoma and the liver in corticotropic pituitary carcinoma [43].

\section{Markers for the diagnosis of aggressive pituitary adenoma}

According to various literature sources, there are several histological markers for early detection of aggressiveness, but none of the markers can definitively predict the clinical and pathological behavior of pituitary neoplasms depending on the type of adenomas. Tumor growth depends on the rate of cell proliferation and loss of control of cell division, which are characteristics for neoplastic behavior.

One of the markers of cell proliferation is the Ki-67 nuclear labeling index, which can distinguish proliferating cells from nonproliferating cells (WHO 2017).

Protein $\mathrm{Ki}-67$ is a cellular proliferation marker and can be used in immunohistochemistry. It is strongly associated with cell proliferation. During interphase, Ki-67 antigen can be found exclusively in the cell nucleus, while during mitosis, most of the protein is transferred to the surface of the chromosomes. Ki- 67 protein is present in all active phases of the cell cycle (G1, S, G2 and mitosis), but absent in resting cells (Go) [51]. A Ki-67 score $\geq 3 \%$ can predict aggressive tumor behavior, and this threshold also serves to distinguish between invasive and non-invasive adenomas with $97 \%$ specificity and $73 \%$ sensitivity $4.44 \mathrm{~A} \mathrm{Ki}-67$ value of $1.5 \%$ is associated with with a decrease in relapse-free survival, 45 and a Ki-67 nuclear index $>10 \%$ is thought to indicate aggressiveness of the pituitary gland [41].

In addition, tumor heterogeneity can lead to different values depending on the sample 47 used, as well as inconsistent results due to different laboratory methods and immunostimulating protocols. For these reasons, the $\mathrm{Ki}-67$ index does not have convincing reproducibility and consensus acceptance.

In addition, invasive and aggressive pituitary adenomas with multiple relapses, as a rule, are associated with p53. Tumor behavior is associated with p53 expression, with immunohistochemically detected expression levels of $0 \%$ in non-invasive pituitary adenomas, $15.2 \%$ in invasive adenomas, and $100 \%$ in pituitary carcinomas [57]. High p53 expression associated with high $\mathrm{Ki}-67$ and nuclear-labeled securin (also known as pituitary tumor transforming gene 1 protein, or PTTG) [34]. High p53 expression may also predict aggressive tumor behavior

\section{Molecular genetic aspects of the development of APA}

Clinically significant embryonic variants of genes of tumor genesis of the pituitary gland are found in up to $20 \%$ of patients with hypertension. The frequency of germline mutations, especially under aggressive conditions, has not yet been determined, but AIP and SDHxgermline mutations are usually associated with more aggressive tumor behavior [12]. APA and PC have been reported in patients with germline mutations, including SDHB, MEN2 and MEN1 [55]. However, PC does not appear to be more common in patients with MEN1 germline mutations than in patients with sporadic pituitary adenomas [53]. As far as 
we know, there have been no reported cases of pituitary carcinoma in patients with AIPassociated familial isolated pituitary adenoma syndrome, type 4 multiple endocrine neoplasia syndrome due to $\mathrm{CDKN1B}$ mutations, Carney complex due to PRKAR1A mutations, McCuneAlbright syndrome GNAS mosaicism or X-linked acrogigantism due to Xq26.3 microduplications involving GPR101.The prevalence of APA is also uncertain in USP8, a gene where somatic mutations have been implicated in Cushing's disease. Early data showed that USP8-mutated corticotrophinomas were smaller with lower plasma ACTH levels, suggesting a milder phenotype. However, subsequent data showed a higher level of free cortisol in urine after surgery in patients with USP8-mutated corticotrophs compared with aggressive corticotrophs, which may be a harbinger of more severe long-term outcomes in these patients [5].

The pathogenetic model of APA also includes the sequence of primary hyperplasia, $\beta$ adenoma, carcinoma with molecular changes, with genetic and epigenetic changes favoring cell survival, proliferation and, ultimately, metastasis [65]. Since most patients have a history of long-term pituitary neoplasms, de novo malignant transformation of normal adenohypophyseal cells seems unlikely.However, there are rare reports of cases of rapid progression from the diagnosis of a pituitary neoplasm to death [39]. The frequent transition of $P C$ from $P A$ through the APA stage suggests that pathogenic mechanisms may be common between PA, APA, and PC. Although, while some genes, such as PTTG, are overexpressed in PA compared to normal pituitary tissue and in PA compared to other PAs [51].

Other genes, such as the RAS gene, appear to be involved only in APA and PC [21]. Although there is some overlap between genetic changes in APT / PC and genes underlying the more common malignant neoplasms of solid organs, mutations in classical oncogenes and tumor suppressor genes are relatively rare [28]. Several molecular mechanisms may be specific for different stages of the pathogenesis of the development of APA.

Transcriptome analysis of lactotropic pituitary neoplasms revealed various genetic changes in purely invasive tumors (upregulation of ADAMTS6 and CRMP1; downregulation of DCAMKL3) compared to tumors that were invasive and aggressive (upregulation of ADAMTS6, CRMP1, PTTB1, ASKUR, CCKN ; downregulated PITX1). The upregulation of Pttg, Aurkb, Cenpe and Crmp and the lack of Pitx1 expression in rat mammary tumors confirmed these findings.

There is a functional basis for the involvement of these genes in ASK, PTTG, AURKB, CCNB1, and CENPE involved in the cell cycle, ADAMTS6 in the extracellular matrix, CRMP in cell migration, and PITX 1 in pituitary differentiation [63].

To date, the role of targeted therapy is being investigated. The use of targeted therapy offers some promise, but data on clinical efficacy are lacking. In vitro data demonstrating upregulation of the Raf / MEK / ERK and $\mathrm{PI} 3 \mathrm{~K}$ / Akt / mTOR pathways in pituitary tumors have not yet led to clinical success in APA [13].

The known PI3K / AKT / mTOR signaling pathway is a signal transduction cascade involved in cell growth and metabolism (Leslie et al., 2001). This pathway is activated by upstream receptor tyrosine kinases (RTKs), which signal through the $\mathrm{PI} 3 \mathrm{~K}$ complex. PI3Kisa is a lipid kinase consisting of regulatory (p85) and catalytic (p110) subunits. It is activated directly through the p85 subunit, which interacts with phosphotitrosine residues on 
tyrosine kinase (RTK) receptors. Alternatively, PI3K interacts with RTK via the adapter proteins IRS1 or IRS2 (White 1998). Both activation methods result in the conversion of $\mathrm{PIP}_{2}$ to a second $\mathrm{PIP}_{3}$ messenger. PIP3 recruits kinases PDK1 and Akt to the plasma membrane [16].

Akt is then phosphorylated by PDK1 and mTORC2 at its threonine and serine residues, respectively. These phosphorylation events lead to the activation of Akt. Akt is a central mediator of the PI3K / AKT / mTOR pathway and phosphorylates several downstream targets that ultimately lead to cell proliferation. These include phosphorylation of a factor that induces apoptosis. (Datta et al. 1997) and FKHR (FOXO1) transcription factors [29] that inhibit apoptosis and promote cell survival, or that abolish the inhibition of proliferative pathways that phosphorylate glycogen synthase kinase-3 [3]. mTOR is another target for Akt phosphorylation and is in the spotlight. mTOR is a kinase that plays an important role in cell growth by modulating cell cycle regulators or maintaining nutrient supply to the cell. It is affected by the Act through the tuberous sclerosis complex (TSC), which consists of two subunits: TSC1 (hamartin) and TSC2 (tuberin) [22]. TSC2 is a negative regulator of $\mathrm{mTOR}$ and $\mathrm{TSC} 2$ phosphorylation by Akt reduces the inhibitory effect of TSC2 on mTOR [67]. Upon activation, mTOR phosphorylates its downstream effectors, including p70S6K and elF4E-binding protein 1, both of which are involved in protein synthesis [37].

The use of tyrosine kinase inhibitors (lapatinib, sunitib, erlotinib) is being considered, and only one case reported a partial response to lapatanib with lactotropic APA [8]. VEGFtargeted therapy with bevacizumab alone or in combination with Tamazolamide (Interleukin-6 imhibitor) has occasionally resulted in partial response or stable disease, although progressive disease has also been reported [31].

Finally, there is interest in the potential use of immunotherapy for the treatment of APA. Pituitary neoplasms, especially APA, have been shown to express programmed death ligand 1 (PD-L1), a T cell immune checkpoint biomarker, along with tumor infiltrating lymphocytes [61].

\section{CONCLUSIONS}

Aggressive pituitary adenomas are a separate group of tumors that need to be evaluated, taking into account all clinical features, as well as histopathological, molecular genetic, and radiological characteristic. Morphological and molecular genetics analyses should predict the aggressive behavior of APA, which is currently a problem all over the world. The study of specific markers of aggressiveness is crucial in the management of patients, prevention of recurrence and progression of adenomas. Moreover, the pathophysiology and diagnosis of aggressive pituitary adenomas should focus on the new studies directed to the potential treatment involved the target specific pathways. Cellular signaling pathway is the main reason of the proliferation and angiogenesis of pituitary adenomas and in the combination with new conventional therapies, it may open up new opportunities for the treatment of AAG.

\section{REFERENCES}

1. Aflorei ED, Korbonits M. Epidemiology and etiopathogenesis of pituitary adenomas. J Neurooncol. 2014;117:379-94

2. Antunes $X$, Ventura $N$, Camilo $G B$, Wildemberg LE, Guasti A, Pereira PJM, et al. Predictors of surgical outcome and early criteria ofremissioninacromegaly.Endocrine.2018;60(3 ):415-22. 
3. Arioka M, Takahashi-Yanaga F. Glycogen synthase kinase-3 inhibitor as a multi-targeting anti-rheumatoid drug. BiochemPharmacol. 2019;165:207-13

4. Asa SL. Pituitary Histopathology in Man: Normal and Abnormal. 2007 Jun 10. In: Feingold KR, Anawalt B, Boyce A, Chrousos G, de Herder WW, Dhatariya K, Dungan K, Grossman A, Hershman JM, Hofland J, Kalra S, Kaltsas G, Koch C, Kopp P, Korbonits M, Kovacs $C S$, Kuohung $W$, Laferrère $B$, McGee $E A$, McLachlan R, Morley JE, New M, Purnell J, Sahay $R$, Singer F, Stratakis CA, Trence DL, Wilson DP, editors. Endotext [Internet]. South Dartmouth (MA): MDText.com, Inc.; 2000

5. Cai $F$, Hong $Y, X u J$, et al. A novel mutation of Aryl hydrocarbon receptor interacting protein gene associated with familial isolated pituitary adenoma mediates tumor invasion and growth hormone hypersecretion. World Neurosurg. 2019;123:e45-e59

6. Cartwright DM, Miller TR, Nasr AJ. Fine-needle aspiration biopsy of pituitary carcinoma with cervical lymph node metastases: a report of two cases and review of the literature. DiagnCytopathol. 1994;11:68-73

7. Chin SO. Epidemiology of Functioning Pituitary Adenomas. EndocrinolMetab (Seoul). 2020 Jun;35(2):237-242. doi: 10.3803/EnM.2020.35.2.237. Epub 2020 Jun 24.

8. Cooper O, Mamelak A, Bannykh S, Carmichael J, Bonert V, Lim S, Cook-Wiens G, Ben-Shlomo A. ProlactinomaErbB receptor expression and targeted therapy for aggressive tumors. Endocrine. 2014;46:318-327

9. Das B, Batool S, Khoja A, Islam N. Presentation, Management, and Outcomes of Nonfunctioning Pituitary Adenomas: An Experience from a Developing Country. Cureus. 2019;11(9):e5759. Published 2019 Sep 25.

10. De Sousa SMC, McCormack Al. Aggressive Pituitary Tumors and Pituitary Carcinomas. [Updated 2018 Nov 26]. In: Feingold KR, Anawalt B, Boyce A, et al., editors. Endotext
[Internet]. South Dartmouth (MA): MDText.com, Inc.; 2000

11. Delgrange, E., Trouillas, J., Maiter, D., Donckier, J. \&Tourniaire, J. Sex-related difference in the growth of prolactinomas: a clinical and proliferation marker study. J. Clin. Endocrinol. Metab. 82, 2012-2107 (1997

12. Dénes J, Swords F, Rattenberry E, et al. Heterogeneous genetic background of the association

of pheochromocytoma/paraganglioma and pituitary adenoma: results from a large patient cohort. J ClinEndocrinolMetab. 2015;100(3):E531-E541.

13. Donovan LE, Arnal AV, Wang SH, Odia Y. Widely metastatic atypical pituitary adenoma with mTOR pathway STK11(F298L) mutation treated with everolimus therapy. CNS Oncol. 2016;5:203-209

14. Dworakowska D, Grossman AB. Aggressive and malignant pituitary tumors: state-of-the-art. EndocrRelat Cancer. 2018

15. Filippella M, Galland F, Kujas M, Young J, Faggiano A, Lombardi G, Colao A, Meduri G, Chanson $P$. Pituitary tumor transforming gene (PTTG) expression correlates with the proliferative activity and recurrence status of pituitary adenomas: a clinical and immunohistochemical study. ClinEndocrinol (Oxf). 2006;65:536-543.

16. Ghigo A, Morello F, Perino A, Hirsch E. Phosphoinositide 3 -kinases in health and disease. SubcellBiochem. 2012;58:183-213.

17. Hamidi O, Van Gompel J, Gruber L, Kittah NE, Donegan D, Philbrick KA, et al. Management and outcomes of Giant Prolactinoma: a series of 71 patients. EndocrPract. 2019;25(4): 340-52.

18. Hardy, J. Transsphenoidal microsurgery of the normal and pathological pituitary. Clin. Neurosurg. 16, 185-217 (1969

19. Imber BS, Lin AL, Zhang Z, Keshavamurthy KN, Deipolyi AR, Beal K, Cohen MA, Tabar V, DeAngelis LM, Geer EB, Yang TJ, Young RJ. Comparison of Radiographic Approaches to 
Assess Treatment Response in Pituitary Adenomas: Is RECIST or RANO Good Enough? J Endocr Soc. 2019 Jul 2;3(9):1693-1706.

20. Kaltsas GA, Nomikos P, Kontogeorgos G, Buchfelder $M$, Grossman AB. Clinical review: Diagnosis and management of pituitary carcinomas. J ClinEndocrinolMetab. 2005;90:3089-3099.

21. Karga HJ, Alexander JM, Hedley-Whyte ET, Klibanski A, Jameson JL. Ras mutations in human pituitary tumors. J ClinEndocrinolMetab. 1992;74:914-919.

22. Khan MA, Jain VK, Rizwanullah $M$, Ahmad J, Jain $\mathrm{K}$. $\mathrm{PI} 3 \mathrm{~K} / \mathrm{AKT} / \mathrm{mTOR}$ pathway inhibitors in triple-negative breast cancer: a review on drug discovery and future challenges. Drug Discov Today. 2019;24:2181-91.

23. Kim JS, Lee YS, Jung MJ, Hong YK. The Predictive Value of Pathologic Features in Pituitary Adenoma and Correlation with Pituitary Adenoma Recurrence. J PatholTransl Med. 2016;50:419-425

24. Knosp E, Steiner E, Kitz K, Matula C. Pituitary adenomas with invasion of the cavernous sinus space: a magnetic resonance imaging classification compared with surgical findings. Neurosurgery. 1993;33(4):610-7;

25. Kovacs K, Horvath E, Vidal S. Classification of pituitary adenomas. J Neurooncol. 2001 Sep;54(2):121-7.

26. Lavrentaki A, Paluzzi A, Wass JA, Karavitaki N. Epidemiology of acromegaly: review of population studies. Pituitary. 2017 Feb;20(1):49.

27. Lelotte J, Mourin A, Fomekong E, Michotte A, Raftopoulos C, MaiterD. Bothinvasivenessandproliferationcriteriapredi ctrecurrence of non-functioning pituitary macroadenomas after surgery: a retrospectiveanalysisofamonocentriccohortof 12opatients.EurJ Endocrinol. 2018;178(3):23746.

28. Lenders N, McCormack A. Malignant transformation in non-functioning pituitary adenomas (pituitary carcinoma). Pituitary. 2018;21:217-229

29. Ma Z, Xin Z, Hu W, Jiang S, Yang Z, Yan X, Li X, Yang $Y$, Chen $F$. Forkhead box $O$ proteins: crucial regulators of cancer EMT. Semin Cancer Biol. 2018;50:21-31.

30. Matsuyama J. Ki-67 expression for predicting progression of postoperative residual pituitary adenomas: correlations with clinical variables. Neurol Med Chir (Tokyo). 2012;52:563-569

31. McCormack A, Dekkers OM, Petersenn S, Popovic V, Trouillas J, Raverot G, Burman P. collaborators ESEs. Treatment of aggressive pituitary tumors and carcinomas: results of a European Society of Endocrinology (ESE) survey 2016. Eur J Endocrinol. 2018;178:265276.

32. Melmed S. Acromegaly pathogenesis and treatment. J Clin Invest. 2009 Nov;119(11):3189202. doi: 10.1172/JCl39375. Epub 2009 Nov 2. PMID: 19884662;

33. Melmed, S. Pathogenesis of pituitary tumors. Nat. Rev. Endocrinol. 7, 257-266 (2011)

34. Mete O, Gomez-Hernandez K, Kucharczyk W, Ridout R, Zadeh G, Gentili F, Ezzat S, Asa SL. Silent subtype 3 pituitary adenomas are not always silent and represent poorly differentiated monomorphousplurihormonal Pit-1 lineage adenomas. Mod Pathol. 2016;29:131-142

35. Mete O, Lopes MB. Overview of the 2017 WHO Classification of Pituitary Tumors. EndocrPathol. 2017 Sep;28(3):228-243.

36. Micko AS, Wohrer A, Wolfsberger S, Knosp E. Invasion of the cavernous sinus space in pituitary adenomas: endoscopic verification and its correlation with an MRI-based classification. J Neurosurg. 2015;122(4):803-11.

37. Moberg M, Apró W, Ekblom B, van Hall G, Holmberg $\mathrm{HC}$, Blomstrand E. Activation of mTORC 1 by leucine is potentiated by branchedchain amino acids and even more so by essential amino acids following resistance exercise. Am J Physiol Cell Physiol. 2016 Jun 
1;310(11):C874-84. doi: 10.1152/ajpcell.00374.2015. Epub 2016 Apr 6.

38. Moisi M, Cruz AS, Benkers T, Rostad S, Broyles FB, Yuen K, Mayberg $M$. Treatment of Aggressive Prolactin-Secreting Pituitary Adenomas with Adjuvant Temozolomide Chemotherapy: A Review. Cureus. 2016;8:e658

39. Nose-Alberti V, Mesquita MI, Martin LC, Kayath MJ. Adrenocorticotropin-Producing Pituitary Carcinoma with Expression of c-erbB-2 and High PCNA Index: A Comparative Study with Pituitary Adenomas and Normal Pituitary Tissues. EndocrPathol. 1998;

40. Oruckaptan HH, Senmevsim O, Ozcan OE, Ozgen T. Pituitary adenomas: results of 684 surgically treated patients and review of the literature. Surg Neurol. 2000;53(3):211-9.

41. Osamura RY, Lopes MBS, Grossman A, Matsuno A, Korbonits M, Trouillas J, Kovacs $K$ (2017) Pituitary adenoma. In: Lloyd RV, Osamura RY, Klöppel G, Rosai J (eds) WHO classification of tumours of endocrine organs, 4th edn. IARC, Lyon, pp 14-18

42. Osamura RY, Tahara $S$, Kurotani R, Sanno N, Matsuno A, Teramoto A. Contributions of immunohistochemistry and in situ hybridization to the functional analysis of pituitary adenomas. J HistochemCytochem. 2000 Apr;48(4):445-58.

43. Pernicone PJ, Scheithauer BW, Sebo TJ, Kovacs KT, Horvath E, Young WF Jr, Lloyd RV, Davis DH, Guthrie BL, Schoene WC. Pituitary carcinoma: a clinicopathologic study of 15 cases. Cancer. 1997;79:804-812

44. Pinto EM, Siqueira SA, Cukier $P$, Fragoso MC, Lin $\mathrm{CJ}$, de Mendonca BB. Possible role of a radiation-induced $\mathrm{p} 53$ mutation in a Nelson's syndrome patient with a fatal outcome. Pituitary. 2011;14:400-404

45. Raverot G, Burman P, McCormack A, Heaney A, Petersenn S, Popovic V, Trouillas J, Dekkers OM. European Society of E. European Society of Endocrinology Clinical Practice Guidelines for the management of aggressive pituitary tumors and carcinomas. Eur J Endocrinol. 2018;178:G1-G24

46. Raverot G, Dantony E, Beauvy J, Vasiljevic A, Mikolasek S, Borson-Chazot F, Jouanneau E, Roy P, Trouillas J. Risk of Recurrence in Pituitary Neuroendocrine Tumors: A Prospective Study Using a Five-Tiered Classification. J ClinEndocrinolMetab. 2017;102:3368-3374

47. Salenave $S$, Ancelle D, Bahougne $T$, Raverot $G$, Kamenicky P, Bouligand J, Guiochon-Mantel A, Linglart A, Souchon PF, Nicolino M, Young J, Borson-Chazot F, Delemer B, Chanson P. Macroprolactinomas in children and adolescents: factors associated with the response to treatment in 77 patients. J ClinEndocrinolMetab. 2015;100:1177-1186.

48. Sanno N, Teramoto A, Osamura RY. Clinical and cytofunctional classification of pituitary adenomas: proposal of a new classification. ActaNeurochir (Wien). 1996;138(10):1186-92.

49. Scheithauer BW, Kurtkaya-Yapicier O, Kovacs KT, Young WF Jr, Lloyd RV. Pituitary carcinoma: a clinicopathological review. Neurosurgery. 2005;56:1066-1074.

50. Scheithauer, B. W., Kovacs, K. T., Laws, E. R. Jr \& Randall, R. V. Pathology of invasive pituitary tumors with special reference to functional classification. J. Neurosurg. 65, 733-744 (1986)

51. Scholzen T, Gerdes J. The Ki-67 protein: from the known and the unknown. J Cell Physiol. 2000 Mar;182(3):311-22.

52. Selman WR, Laws ER Jr, Scheithauer BW, Carpenter SM. The occurrence of dural invasion in pituitary adenomas. J Neurosurg. 1986;64(3):402-7.

53. SrirangamkimNadhamuni $V$, Korbonits $M$. Novel Insights into Pituitary Tumorigenesis: Genetic and Epigenetic Mechanisms. Endocr Rev. 2020;41(6):821-846.

54. Tanizaki Y, Jin L, Scheithauer BW, Kovacs K, Roncaroli F, Lloyd RV. P53 gene mutations in pituitary carcinomas. EndocrPathol. 2007;18:217-222 
55. Tatsi C, Stratakis CA. The Genetics of Pituitary Adenomas. J Clin Med. 2019;9(1):30.

56. Thapar K, Scheithauer BW, Kovacs K, Pernicone PJ, Laws ER Jr. p53 expression in pituitary adenomas and carcinomas: correlation with invasiveness and tumor growth fractions. Neurosurgery. 1996 Apr;38(4):765-70; discussion 770-1.

57. Thapar, K. et al. Proliferative activity and invasiveness among pituitary adenomas and carcinomas: an analysis using the MIB-1 antibody. Neurosurgery 38, 99-106 (1996).

58. Trouillas J, Roy P, Sturm N, Dantony E, CortetRudelli C, Viennet $G$, Bonneville JF, Assaker R, Auger $C$, Brue $\mathrm{T}$, Cornelius A, Dufour $\mathrm{H}$, Jouanneau E, Francois P, Galland F, Mougel F, Chapuis F, Villeneuve L, Maurage CA, FigarellaBranger $D$, Raverot $G$, Barlier $A$, Bernier $M$, Bonnet F, Borson-Chazot F, Brassier G, CauletMaugendre S, Chabre O, Chanson P, Cottier JF, Delemer B, Delgrange E, Di Tommaso L, Eimer S, Gaillard S, Jan M, Girard JJ, Lapras V, Loiseau $\mathrm{H}$, Passagia JG, Patey M, Penfornis A, Poirier JY, Perrin G, Tabarin A. A new prognostic clinicopathological classification of pituitary adenomas: a multicentric case-control study of 410 patients with 8 years post-operative follow-up. ActaNeuropathol. 2013;126:123-135.

59. Trouillas, J. et al. A new prognostic clinicopathological classification of pituitary adenomas: a multicentric case-control study of 410 patients with 8 years post-operative follow-up. ActaNeuropathol. 126, 123-135 (2013).

60. Vilar L, Vilar CF, Lyra R, Lyra R, Naves LA. Acromegaly: clinical features at diagnosis. Pituitary. 2017 Feb;20(1):22-32.

61. Wang PF, Wang TJ, Yang YK, Yao K, Li Z, Li YM, Yan CX. The expression profile of PD-L1 and CD8(+) lymphocyte in pituitary adenomas indicating for immunotherapy. J Neurooncol. 2018

62. Wei X, Luo L, Chen J. Roles of mTOR signaling in tissue regeneration. Cells. 2019;8:E1075.
63. Wierinckx A, Auger C, Devauchelle P, Reynaud $A$, Chevallier $P$, Jan $M$, Perrin $G$, FevreMontange $M$, Rey $C$, Figarella-Branger $D$, Raverot G, Belin MF, Lachuer J, Trouillas J. A diagnostic marker set for invasion, proliferation, and aggressiveness of prolactin pituitary tumors. EndocrRelat Cancer. 2007;14:887-900.

64. World Health Organization Classification of Tumors of Endocrine Organs. 4th ed. Lyon: IARC Press; 2017.

65. Yakoushina TV, Lavi E, Hoda RS. Pituitary carcinoma diagnosed on fine needle aspiration: Report of a case and review of pathogenesis. CytoJournal. 2010;7:14.

66. Yakoushina TV, Lavi E, Hoda RS. Pituitary carcinoma diagnosed on fine needle aspiration: Report of a case and review of pathogenesis. CytoJournal. 2010;7:14.

67. Yoo F, Kuan EC, Heaney AP, Bergsneider M, Wang MB. Corticotrophic pituitary carcinoma with cervical metastases: case series and literature review. Pituitary. 2018;21:290-301.

68. Zhang J, Zhang JX, Zhang QL. PI3K/AKT/mTORmediated autophagy in the development of autism spectrum disorder. Brain Res Bull. 2016 Jul;125:152-8. 